\title{
DIMENSÕES DA CULTURA, POLÍTICAS PÚBLICAS E DESENVOLVIMENTO: PROPOSIÇÕES TEÓRICAS À LUZ DO EMPREENDEDORISMO NAS INDÚSTRIAS CRIATIVAS
}

Jorge Cleber Pereira Da Silva ${ }^{1}$ Alexandre Rabelo Neto $^{2}$

lara Marques Do Nascimento ${ }^{3}$

\footnotetext{
${ }^{1}$ Centro de Ciências Humanas e Letras / Universidade Federal do Piauí

${ }^{2}$ Universidade Federal do Piauí

${ }^{3}$ Instituto Federal de Educação, Ciência e Tecnologia do Sudeste de Minas Gerais
} 


\section{DIMENSÕES DA CULTURA, POLÍTICAS PÚBLICAS E DESENVOLVIMENTO: PROPOSIÇÕES TEÓRICAS À LUZ DO EMPREENDEDORISMO NAS INDÚSTRIAS CRIATIVAS}

Resumo: Este artigo discute as relações entre cultura e desenvolvimento sob o ponto de vista das indústrias criativas, além de apresentar suas dimensões, as quais são relevantes para a formulação de políticas públicas de modo a evitar que as mesmas sejam reduzidas apenas a boas intenções. Destaca que as atividades culturais e criativas são apontadas como estratégica para o crescimento e o desenvolvimento econômico e social de países desenvolvidos e em desenvolvimento através da geração de emprego e renda e por meio da promoção da inclusão social, da diversidade cultural e do desenvolvimento humano. Aponta ainda que apesar do seu efetivo potencial de crescimento, as indústrias criativas têm encontrado obstáculos que impedem sua expansão, como a baixa disponibilidade de recursos financeiros e a pouca infraestrutura no que se refere à distribuição e difusão dos bens e serviços.

Palavras-chave: Dimensões da Cultura. Indústria Criativa. Políticas Públicas. Desenvolvimento.

\section{Introdução}

Durante boa parte da história da humanidade, as questões culturais mantiveram estreito relacionamento com a ordem privada da vida dos indivíduos, distanciando-se, deste modo, de temas associados à economia. Todavia, com a percepção do homem de que o capital econômico não é gerado apenas pelas atividades industriais clássicas (tais como siderúrgicas, têxteis, alimentícias, dentre outros), mas também pela produção e comercialização de símbolos e atividades baseadas na criatividade individual e coletiva, recentemente a cultura passou a ser objeto privilegiado de análise no campo econômico (BRASIL; ALVES; ALVES, 2013).

Silva (2012) afirma que o interesse na temática da cultura e em sua articulação com propostas e concepções de desenvolvimento é crescente e abre diversas possibilidades de abordagem e discussão. Seja na economia gerada pela produção, circulação e consumo de bens culturais, ou na ideia de cultura como a dimensão capaz de apontar os caminhos para o desenvolvimento de uma sociedade, o que se evidencia nos últimos anos é a recorrência constante à cultura para pensar o desenvolvimento.

\section{Organizadores:}
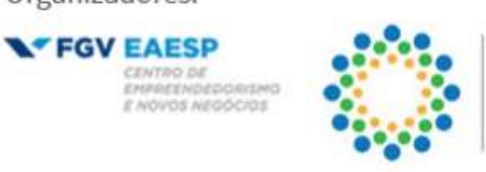

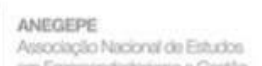

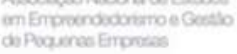
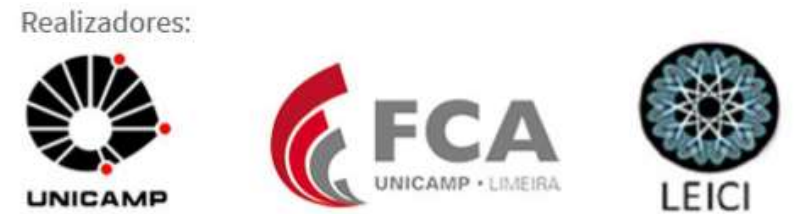
Classicamente compreendida como o processo de desenvolvimento e enobrecimento das faculdades humanas (THOMPSON, 2009), a cultura, sobretudo nas suas interfaces com a Desenvolvimento do trabalho dimensão econômica, possibilitou evidenciar a temática das indústrias criativas, surgidas como uma ampliação do conceito de indústrias culturais e a partir das quais se desenvolve a economia criativa (REIS, 2008).

Nesse novo paradigma, torna-se necessário compreender a cultura e suas dimensões no sentido de apontar novos caminhos para as políticas públicas de apoio à atividade cultural e criativa com foco no desenvolvimento (BOTELHO, 2016). Além disso, diante das possibilidades apresentadas pela nova economia, a criativa, torna-se fundamental o entendimento do processo de transição por qual passa a economia mundial, a partir da observação dos fundamentos teóricos e dos motivadores globais que compõem a estrutura das indústrias criativas e sua economia (PROCOPIUCK; FREDER, 2013).

Some-se a isso o fato de que, nos últimos anos, as indústrias criativas tornaram-se foco das discussões de órgãos e comunidades internacionais, sendo apontadas como estratégicas para o crescimento e o desenvolvimento econômico e social de países desenvolvidos e em desenvolvimento, quer seja através da geração de emprego e renda, quer seja por meio da promoção da inclusão social, da diversidade cultural ou do desenvolvimento humano (LEITÃO et al., 2011).

Valiati e Moller (2016) afirmam que a implementação de políticas públicas para o fomento das atividades culturais e criativas com objetivos de desenvolvimento socioeconômico e territorial é relativamente recente no Brasil. Além disso, Procopiuck e Freder (2013) apontam a relevância da formulação e implementação de políticas públicas para preservação de riquezas culturais e a inserção da cultura associada à criatividade como componentes de bens e serviços tecnologicamente avançados.

Tendo em vista a importância dos estudos no que se refere às atividades culturais $\mathrm{e}$ criativas numa perspectiva de pensamento econômico desenvolvimentista, estabeleceu-se o seguinte problema de pesquisa: Qual a relação existente entre indústrias criativas e desenvolvimento? Com o objetivo de responder a esse questionamento, o presente estudo tem como objetivo geral discutir perspectivas teóricas que comprovam a forte relação entre cultura e desenvolvimento, analisadas sob o ponto de vista das indústrias criativas. E, como objetivos específicos: a) apresentar as dimensões da cultura e suas implicâncias no processo de formulação de políticas públicas; b) identificar os fatores limitantes do desenvolvimento das indústrias criativas e; c) apontar quais os impactos positivos das atividades culturais e criativas para o desenvolvimento.

No entanto, apesar da existência de publicações sobre as relações entre cultura, indústrias criativas e desenvolvimento em diversos países, as investigações sobre os temas no contexto brasileiro encontram-se em estágio de crescimento. Assim, torna-se relevante a realização deste e de outros estudos para uma melhor explicitação dessas relações, as quais

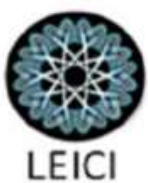


podem fundamentar a elaboração de políticas públicas para o desenvolvimento da atividade econômica de base cultural ou criativa (LEITÃO et al., 2011; PACHECO; BENINI, 2015; VALIATI; MOLLER, 2016).

Para cumprir seu intuito, este artigo está estruturado em quatro capítulos. O primeiro trata da introdução, onde é apresentado o contexto em que se situa o estudo, seu objetivo e justificativa. No segundo capítulo são apresentadas as dimensões da cultura e as implicâncias destas sobre a formulação de políticas públicas. No terceiro capítulo são apresentadas as relações entre atividades culturais, indústrias criativas e desenvolvimento. No último capítulo são enumeradas algumas conclusões do estudo, bem como limitações e possibilidades para estudos futuros.

\section{Dimensões da Cultura e Políticas Públicas}

Cultura é um conceito que se movimenta indefinidamente, na história das ciências humanas e sociais, tendo várias interpretações e usos. Ela pode ser compreendida a partir de dimensões ou acepções várias em razão de as percepções acerca dela estarem em constante transformação. Além disso, tem-se observado o aumento do número de estudos e a inserção da temática cultural em áreas diversas que vão da economia à política. Neste sentido, a cultura adquiriu, na atualidade, um lugar relevante, o qual transborda os limites de um campo social específico, adquirindo, deste modo caráter transversal que perpassa toda a complexa sociabilidade contemporânea (RUBIM, 2010).

Diante do exposto, Albuquerque Junior (2017, p. 17) afirma que

O que chamamos de cultura, conceito que por seu uso no singular já demonstra sua prisão à lógica da identidade, é na verdade um conjunto múltiplo e multidirecional de fluxos de sentido, de matérias e formas de expressão que circulam permanentemente, que nunca respeitaram fronteiras, que sempre carregam em si a potência do diferente, do criativo, do inventivo, da irrupção, do acasalamento. Na verdade nunca temos cultura: temos trajetórias culturais, fluxos culturais, relações culturais, redes culturais, conexões culturais, conflitos, lutas culturais. As classes ou grupos sociais hegemônicos é que, muitas vezes, querem fazer de suas manifestações culturais a cultura.

Diante do exposto, para se chegar à compreensão necessária sobre o papel da cultura no tempo e no espaço, é válido um breve panorama sobre ela. O ponto de partida é o século XVIII, com o Iluminismo. Neste período, a cultura era associada ao cultivo do espírito, das artes, das letras e da ciência. Entre os séculos XIX e XX surge o conceito antropológico de cultura, que passa a ser compreendida enquanto estudo do modo de vida de uma comunidade, conferindo-se importância a elementos como valores, crenças, rituais e símbolos (GODOY; SANTOS, 2014).

Rubim (2007) observa que durante a modernidade, o campo cultural adquiriu relativa autonomia em relação a outras áreas, como a religião e a política, constituindo-a como campo

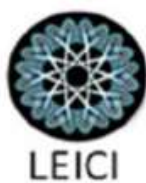


singular que articula e inaugura instituições, profissões, linguagens, símbolos, valores, tensões e conflitos. Nesse período há ainda o processo de politização da cultura, o qual pode ser entendido como o processo por meio do qual significados produzidos por setores sociais subalternizados afetam e desestabilizam arranjos de poder social dominante (ALVAREZ; DAGNINO; ESCOBAR, 2000).

Na passagem da modernidade para a contemporaneidade, tem-se a ocorrência de outro marco para o campo cultural: a mercantilização da cultura, ligada ao desenvolvimento do capitalismo e da indústria cultural. Ao processo de conversão da cultura em mercadoria e ao processo de subordinação da consciência a racionalidade capitalista deu-se o nome de indústria cultural. Para Rüdiger (2001, p.138), a expressão indústria cultural designa, "uma prática social, através da qual a produção cultural e intelectual passa a ser ordenada em função de sua possibilidade de consumo no mercado".

Neste sentido, Weber (1998, p. 146) informa que "a cultura, reduzida a simples valor de troca, deixa de prestar-se à reflexão crítica sobre as condições de existência em que vivem os homens para servir aos propósitos de perpetuação do status quo por meio da acomodação e do conformismo".

A década de 60 é um período de transição e sugere que momentos de grande ruptura não costumam envolver mudanças totais de conteúdo e sim a reestruturação de elementos que já existem. Assim, questões que eram subordinadas em determinando momento tornam-se dominantes e vice-versa. $\mathrm{O}$ autor utiliza o conceito de pós-modernismo para designar o papel da cultura, observando-o como uma lógica cultural capaz de conduzir à transformação da esfera cultural na sociedade contemporânea (JAMENSON, 2006).

Cita-se, ainda, como pontos marcantes para a compreensão da cultura na atualidade a "culturalização da política" e a "culturalização da mercadoria". Enquanto a primeira expressão aponta que "o cenário da política contemporânea se amplia, ao incorporar, por demandas societárias, novos temas, muitos deles de forte impregnação cultural", a segunda registra "o crescente papel de componentes simbólicos na determinação do valor das mercadorias, mesmo sob o formato de bens materiais" (RUBIM, 2007, p.144), fazendo emergir, deste modo, estudos sobre economias ou indústrias criativas.

É válido destacar que, em relação às indústrias criativas, Botelho (2001) também faz uma diferenciação entre processos relacionados à cultura e à arte. Ela aponta que as mudanças não são ingredientes básicos para a cultura, em sua dimensão mais ampla, como é para as artes. Pois, na cultura, as mudanças operam de forma mais lenta e

embora as artes sejam parte da cultura, a criatividade é um elemento intrínseco a elas e seus efeitos podem ser sentidos quase em sincronia, ou seja, numa temporalidade abreviada ou imediata. Seguindo esse raciocínio, as artes e os princípios que as regem são mais cruciais para os discursos sobre as indústrias criativas - mais compatível em seu diálogo prioritário com o mercado - do que a cultura (BOTELHO, 2011, p. 81).

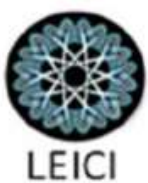


Deste modo, para efeito deste trabalho, concebe-se a cultura a partir de duas dimensões: a antropológica e a sociológica, as quais diferenciam a cultura no plano cotidiano e a que ocorre no circuito organizado. Essa apresentação faz desaguar a primeira proposição teórica do estudo, a saber:

P1 A compreensão das diferenças das dimensões da cultura é de suma importância para a formulação e implementação de políticas públicas culturais.

Botelho (2016) afirma que essa distinção é necessária para melhor observação e construção de políticas públicas ligadas à cultura, além de ampliar os entendimentos de práticas e produções culturais engendradas pelas indústrias criativas. A autora acrescenta que a distinção entre as duas dimensões é determinante para o tipo de investimento a ser feito pelo governo uma vez que há possibilidade se trabalhar com um conceito amplo de cultura ou delimitando um universo específico como o das artes para objeto de atuação. Cada uma oferece definições e parâmetros para a construção de políticas culturais, cada qual com suas estratégias.

Para a dimensão antropológica, a cultura é produzida por meio da interação social dos indivíduos, construindo e reconstruindo modos de pensar, agir, identidades e diferenças, elaborando valores e estabelecendo rotinas. Assim, a cultura é entendida como "o modo de vida particular de um grupo definido" (MINTZ, 2010, p. 230).

Nessa construção - que pode dá-se em razão das origens regionais, interesses profissionais ou econômicos, de gênero ou outros - a interação é um dado fundamental e a sociabilidade é um dado básico. Além disso, para que a cultura seja atingida por uma política, nessa dimensão, é preciso haver uma reorganização das estruturas sociais e distribuição de recursos econômicos, ocasionando interferências nos estilos e na qualidade de vida da sociedade (BOTELHO, 2016).

A dimensão sociológica, por sua vez, se constitui na esfera especializada, sendo uma "produção elaborada com a intenção explícita de construir determinados sentidos e de alcançar algum tipo de público, através de meios específicos de expressão" (BOTELHO, 2001, p. 74). A autora acrescenta que para a realização dessa intenção é preciso que um conjunto de fatores forneça ao indivíduo condições de desenvolvimento e aperfeiçoamento de seus talentos e de canais em que possa expressá-los. Em outras palavras, a dimensão sociológica da cultura

se refere a um conjunto diversificado de demandas profissionais, amadoras, institucionais, políticas e econômicas, o que a torna visível e palpável. Ela é composta por circuitos organizacionais variados e complexos, passando a ser naturalmente o foco de atenção das políticas culturais, deixando o plano antropológico relegado simplesmente ao discurso, já que é menos palpável (BOTELHO, 2016, p. 22).

\section{Organizadores:}
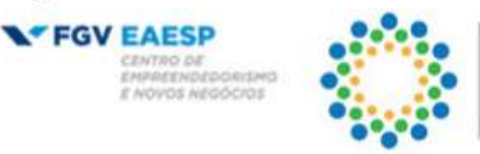

ANEOEPE

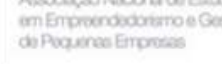
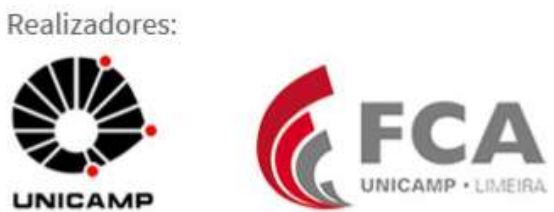
Trata-se de um processo que estimula a produção, a circulação e o consumo de bens simbólicos por vários meios, tendo na cultura um entendimento de senso comum capar de criar um circuito socialmente organizado, no qual é possível planejar interferências e buscar resultados com relativa previsibilidade.

Segundo Botelho (2001), o fato de ser institucionalizada, faz com que essa dimensão seja privilegiada em relação às políticas culturais, pois, oferece um circuito mais visível e palatável . A autora também observa que essa dimensão permite que as políticas tenham uma ação efetiva, já que permite a elaboração de diagnósticos para atacar problemas de forma programada, estimar recursos e resolver carências com metas de curto, médio e longo prazo. Mas, estas mesmas políticas não conseguem, isoladamente, atingir o plano do cotidiano.

Para atingir a dimensão antropológica, as políticas culturais precisam de dois tipos de investimento: "estratégias do ponto de vista da demanda" e "área de cultura dentro do aparato governamental". A primeira demanda organização e atuação efetiva da sociedade, exigindo a resposta e presença dos poderes públicos em relação a questões concretas específicas da área de cultura. $\mathrm{O}$ segundo diz respeito à delimitação do universo de atuação da política cultural a ser estabelecida, tendo estratégias específicas para atuação na dimensão antropológica (BOTELHO, 2016).

Nesse contexto, as políticas públicas no âmbito da cultura, para serem efetivadas precisam definir, com clareza, seu campo de atuação, de modo a não gerar ilusão e evitar projetos que fiquem apenas no plano do papel, reduzidos, dessa forma, a boas intenções.

\section{Economia Criativa e Atividades Culturais para Pensar o Desenvolvimento}

Segundo Paglioto (2016), a Economia Criativa e seus variantes emergiram a partir das últimas duas décadas como um discurso no âmbito das políticas econômicas e culturais. Ela está relacionada ao desenvolvimento da economia e das sociedades modernas atuais na medida em que o capital intelectual se torna cada vez mais relevante para o desenvolvimento de novos produtos e mercados (COSTA; SOUZA-SANTOS, 2011).

Surge como área de conhecimento e como campo de atuação prática que abrange desde níveis macro até níveis micro, requerendo abordagens multidisciplinares e políticas inovadoras para impulsionar indústrias, cidades e nações criativas (PROCOPIUCK; FREDER, 2013).

Nesta linha de pensamento, Howkins (2013) informa que a economia criativa é constituída por setores cuja origem está na criatividade, no conhecimento e no talento, individual e coletivo, características que possuem potencial para a criação de riqueza e empregos, através da geração e exploração de ativos criativos, como a propriedade intelectual. Assim, a economia criativa atua como elemento articulador da criatividade, tecnologia e inovação, onde a criatividade é a força motriz e a tecnologia da informação sua principal infraestrutura (NICOLACI-DA-COSTA (2011).

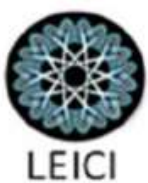


Para Reis (2008), a criatividade pode ser entendida como um combustível renovável que se propaga conforme o uso, possibilitando ao indivíduo unir pontos desconexos, ou equacionar soluções para novos e velhos problemas. Deste modo, a criatividade centra-se no uso de ideias para produzir novas ideias (OLIVEIRA; ARAÚJO; SILVA, 2013).

A United Nations Conference on Trade and Development considera o uso da economia criativa vantajosa uma vez que permite que cada país, região ou localidade explore habilidades, conhecimentos tradicionais e heranças culturais para fomentar o setor criativo e, ao mesmo tempo, promover a identidade cultural e auxiliar na inserção de atividades criativas nos setores de maior crescimento da sociedade contemporânea (UNCTAD, 2011). Deste modo, a segunda proposição teórica é:

P2 As indústrias criativas e sua economia reduzem o desemprego, promovem a inclusão social e o desenvolvimento humano.

Nos últimos anos, as indústrias criativas têm sido utilizada para promover crescimento econômico, desenvolvimento (VALIATI; WINK JUNIOR, 2013) e fomentar a inovação, sobressaindo-se como uma importante estratégia tanto para a redução do desemprego, promoção da inclusão social e do desenvolvimento humano como também para a melhoria dos níveis de competitividade de países, regiões e localidades (PROCOPIUCK; FREDER, 2013).

Ela ajuda a reavivar áreas urbanas decadentes, a abrir e desenvolver áreas rurais remotas e a promover a preservação dos recursos ambientais e patrimônios culturais de um país (SECRETARIA DA ECONOMIA CRIATIVA/MINC, 2012).

\subsection{Economia Criativa e Indústria Cultural}

Na obra Creative Industries, Hartley (2005) diz que economia criativa é a convergência conceitual e prática das artes criativas com as indústrias culturais no contexto das novas tecnologias das mídias dentro de uma nova economia do conhecimento. Diante disso, a segunda proposição do estudo é:

P3 A economia criativa é um mecanismo alternativo para criar, produzir $e$ distribuir bens e serviços culturais com potencial de gerar benefícios econômicos $e$ sociais significativos.

Dentro desta premissa, a cultura, além de impulsionar pequenas empresas e empreendimentos familiares em pequenos núcleos urbanos, contribui para a coletividade com a preservação de práticas tradicionais e abertura de oportunidades para grupos sociais menos favorecidos pela economia tradicional (PROCOPIUCK; FREDER, 2013).

Em termos de impacto mais amplo no desenvolvimento econômico e social, a mobilização econômica de ativos culturais comunitários pode contribuir para o

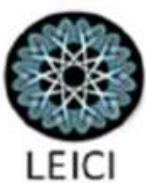


desenvolvimento local sustentável até a constituição de indústrias culturais, trazendo em contrapartida a revitalização social, cultural e econômica (UNESCO, 2009).

Ressalta-se que as atividades culturais e criativas consolidam-se pela amplitude de bens e serviços simbólico-culturais que geram e pelo poder econômico e de mobilização social que as caracterizam. O desenvolvimento dessas áreas contribui para o desenvolvimento social, a formação de identidade de uma nação e sua autonomia (UNCTAD, 2010).

Ademais, existe um alto consenso doutrinal apontando para o fato de que a cultura cria externalidades positivas e que seu consumo é "viciador", estando condicionado pela educação (ASUAGA, 2013). Além disso, o consumo de bens patrimoniais, em suas diversas expressões, influencia na revalorização de valores simbólicos compartilhados, na coesão social e na identidade dos indivíduos.

Nesses termos, sustenta-se que a economia criativa é uma construção simbólicodiscursiva acerca da esfera cultural, fazendo nascer um agudo discurso culturalista no ambiente empresarial-corporativo e governamental. A categoria de economia criativa é, por si só, instauradora de novas realidades e dinâmicas econômico-culturais, uma vez que tem sido demasiadamente utilizada para justificar e executar políticas culturais em países como o Brasil (ALVES; SOUSA, 2012).

\subsection{Indústria Criativa como Política Pública para o Desenvolvimento}

A importância econômica das indústrias criativas é crescente e, em razão disso tem sido objeto de políticas públicas de desenvolvimento (HOWKINS, 2001; HARTLEY, 2005). Tal fenômeno designa setores nos quais a criatividade é uma dimensão essencial do negócio e compreendem, entre outras, as atividades relacionadas ao cinema, ao teatro, à música e às artes plásticas.

Na percepção de Lugoboni et al (2014), as indústrias criativas estão entre os setores mais dinâmicos da economia e são caracterizadas como aquelas que valorizam o capital intelectual, investem tecnologia e inovação que unidos representam oportunidades para indivíduos, empresas e cidades para gerar crescimento econômico e desenvolvimento.

Deste modo, as indústrias criativas abrangem processo de criação, produção, comercialização e distribuição de bens e serviços, frutos da criatividade humana e da aplicação de capital intelectual, e têm por finalidade criar valor econômico e cultural, conteúdo criativo e realizar objetivos de mercado. São indústrias que fazem interface entre atividades econômicas com base no conhecimento e, caracteristicamente, trabalham com bens tangíveis e realização de serviços intelectuais intangíveis (UNCTAD, 2011). Uma visão completa das indústrias criativas pode ser obtida através da observação da Figura 1. 
Figura 1: Classificação das Indústrias Criativas

\section{Indústrias Criativas}

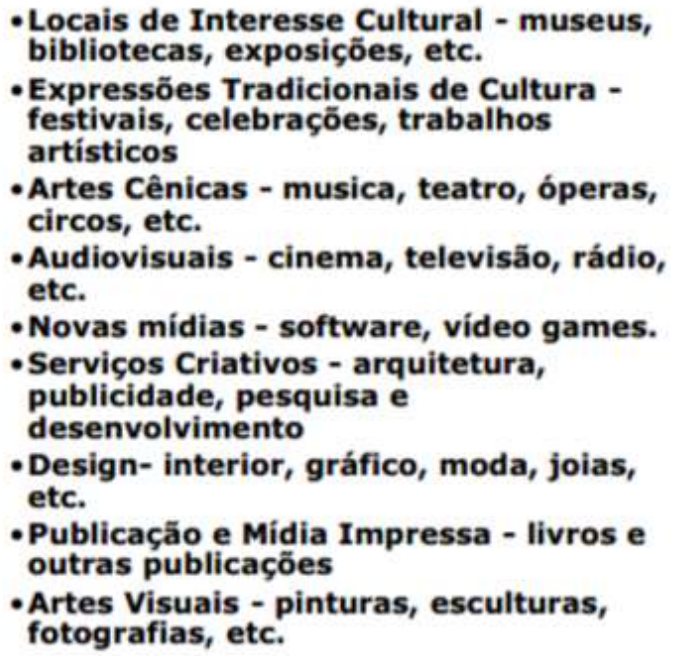

Fonte: Adaptado de UNCTAD (2010)

Embora as políticas de apoio à inovação tecnológica e difusão do conhecimento possam contribuir para o crescimento econômico e desenvolvimento, os conjuntos apropriados de políticas para fomento da economia criativa, pequenos empreendimentos e valorização da cultura podem propiciar um ambiente fértil para o desenvolvimento de novas empresas e fortalecimento da economia local (ARAGÃO et al., 2017). Em razão disso, a quarta e a quinta premissas do estudo são:

P4 As indústrias criativas encontram nas políticas públicas vetores para o seu surgimento.

P5 As indústrias criativas encontram barreiras que impedem o seu desenvolvimento, as quais podem ser minimizadas através da formulação e implementação de políticas públicas para o setor.

No entanto, apesar do seu efetivo potencial de crescimento, a indústria criativa tem encontrado obstáculos que impedem sua expansão, os quais citam-se a baixa disponibilidade de recursos financeiros para o financiamento de negócios desta natureza, o baixo investimento em capacitação dos agentes atuantes na cadeia produtiva destas indústrias e pouca infraestrutura no que se refere à distribuição e difusão dos bens e serviços (LEITÃO et al., 2011; LUGOBONI et al., 2014).

Pacheco e Benini (2015) acrescentam ainda que as possibilidades de avanço na adoção de medidas de incentivo e de fortalecimento de iniciativas presentes na indústria criativa 
brasileira esbarram no processo de reconhecimento efetivo de suas potencialidades e desdobramentos, bem como na ausência de estudos e informações que consolidem a economia criativa como aquela capaz de promover desenvolvimento econômico, social e cultural, equitativo, inclusivo e sustentável.

Assim, faz-se necessário um maior entendimento do processo de incorporação do conceito de indústrias criativas em políticas públicas, tanto do ponto de vista da compreensão de ações voltadas para as indústrias criativas como um todo (ou seja, políticas que visem, por exemplo, fomentá-las num dado território) quanto para áreas criativas específicas, ainda que não estejam inseridas necessariamente numa lógica industrial (BENDASSOLLI et al., 2009).

Novy e Colomb (2013) apontam que as políticas públicas de incentivo à indústria criativa são necessárias e urgentes. Além disso, o desenvolvimento dos pontos de indústria criativa nas cidades permite torná-la mais competitiva em razão do fortalecimento do empreendedorismo.

Neste sentido, Leitão et al (2011) afirmam que o Brasil, reconhecido pela sua diversidade cultural e potencial criativo, sofre com vários obstáculos no que se refere à consecução da indústria criativa como política de desenvolvimento. Os autores apontam que são necessárias políticas públicas que promovam apoio à profissionalização desses novos negócios, estruturação de infraestrutura para a circulação e difusão de bens e serviços criativos, além da concessão de crédito como apoio ao investimento no setor.

Baumol e Bowen (1965) acrescentam que a produção e a oferta de bens e serviços culturais necessitavam de subsídios do Estado, uma vez que os mesmos apresentam potencialidades econômicas. Neste sentido, concebe-se a cultura como uma indústria, um complexo midiático-mercantil funcionando como um dos principais motores do crescimento das nações desenvolvidas (LIPOVETSKY; SERROY, 2011).

Além disso, é importante que as políticas públicas para o setor (como um todo ou para áreas específicas) sejam consideradas sob a ótica da análise de redes sociais, para que se conheçam as relações que se estabelecem em torno delas, por meio dos diversos atores envolvidos na sua concepção (JAMBEIRO; FERREIRA, 2012).

\section{Considerações Finais}

$\mathrm{Na}$ atualidade, em decorrência das transformações do mundo globalizado e pósindustrializado, a cultura e suas dimensões passaram a ser objeto de análise no campo das políticas públicas em razão do impacto que as mesmas têm sobre o desenvolvimento socioeconômico de países e regiões.

Diante disso, este trabalho discutiu perspectivas teóricas que relacionam os campos da cultura, das políticas públicas e do desenvolvimento sob o enfoque das indústrias criativas, as quais podem ser entendidas como empreendimentos que dependem da capacidade individual de se apropriar da cultura local de sua região ou país para a aplicação de novas ideias para a
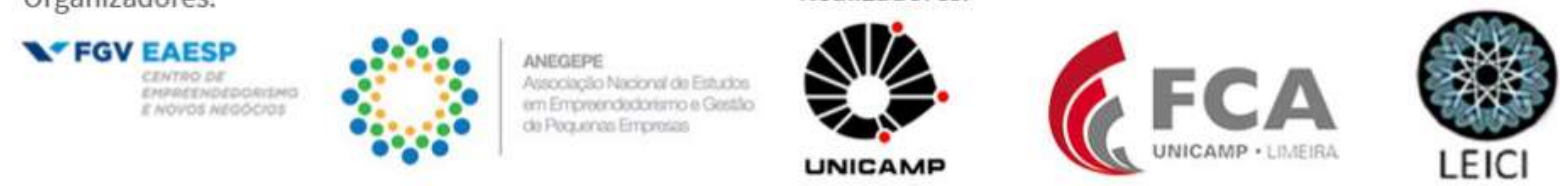
produção de obras de arte e produtos culturais, criações funcionais, invenções científicas e inovações tecnológicas.

As proposições discutidas nessa pesquisa foram: P1 - A compreensão das diferenças das dimensões da cultura é de suma importância para a formulação e implementação de políticas públicas culturais; P2 - As indústrias criativas e sua economia reduzem o desemprego, promovem a inclusão social e o desenvolvimento humano; P3 - A economia criativa é um mecanismo alternativo para criar, produzir e distribuir bens e serviços culturais com potencial de gerar benefícios econômicos e sociais significativos; P4 - As indústrias criativas encontram nas políticas públicas vetores para o seu surgimento; P5 - As indústrias criativas encontram barreiras que impedem o seu desenvolvimento, as quais podem ser minimizadas através da formulação e implementação de políticas públicas para o setor.

Essas proposições teóricas desembocam no modelo teórico abaixo apresentado o qual precisa ser testado empiricamente em futuros estudos.

Figura 2: Modelo proposto para o estudo

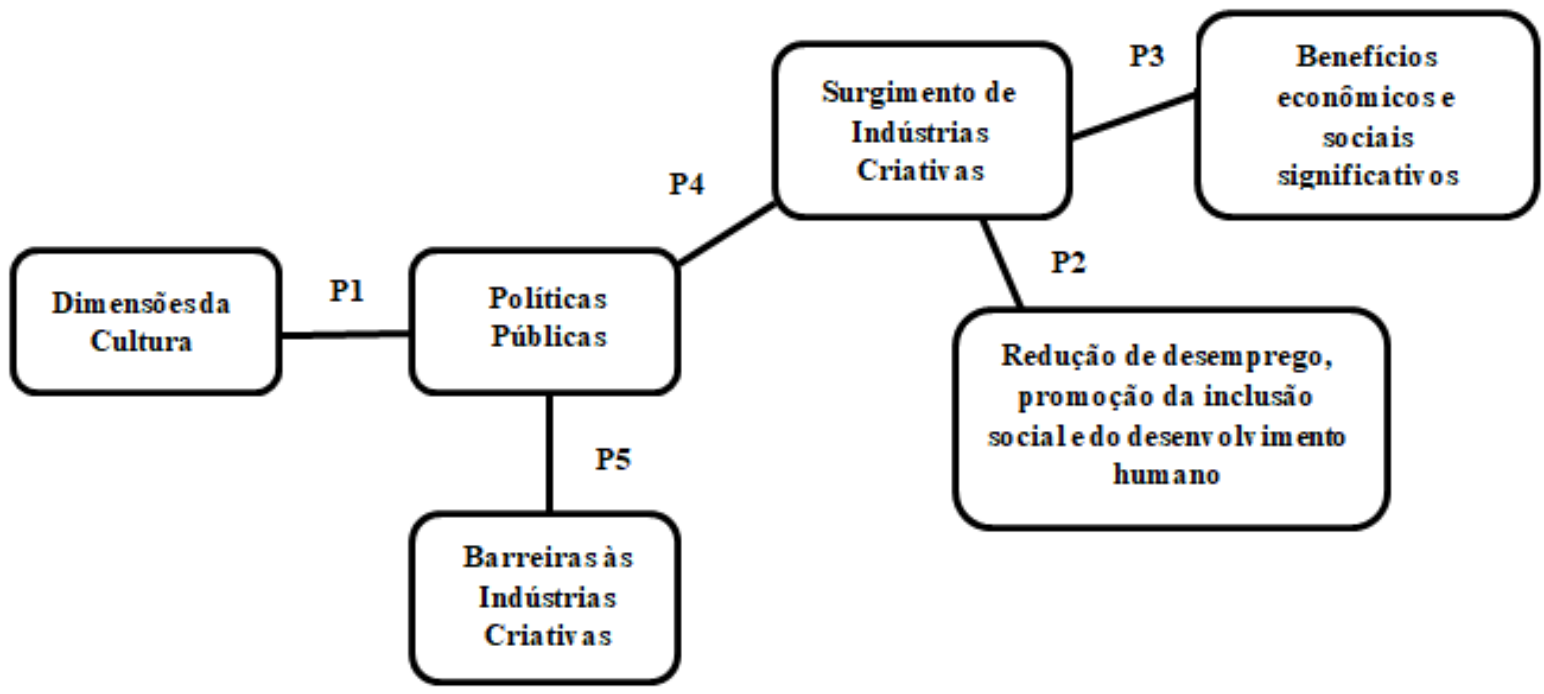

Fonte: Próprios autores (2018)

Portanto, recomenda-se que pesquisas futuras busquem testar as proposições surgidas a partir desse estudo, com a finalidade de ampliar o entendimento sobre os relacionamentos encontrados, a partir da literatura, no que tange às dimensões da cultura, políticas públicas e desenvolvimento, tendo como ponto de referência o contexto das indústrias criativas e sua economia.

\section{REFERÊNCIAS}

Organizadores:
NFGV EAESP


ALBUQUERQUE JUNIOR, D. M. C. Fragmentos do discurso cultural: por uma análise crítica do discurso sobre a cultura no Brasil. In: NUSSBAUMER, G. M. (Org.). Teorias e políticas da cultura: visões multidisciplinares. Salvador: EDUFBA, 2007, p.139-158.

ALVAREZ, S. E.; DAGNINO, E.; ESCOBAR, A. (org.). Cultura e política nos movimentos sociais latino-americanos: novas leituras. Belo Horizonte: UFMG, 2000.

ALVES, E. P. M.; SOUZA, C. A. C. A economia criativa no Brasil: o capitalismo cultural brasileiro contemporâneo. Latitude, v. 6, n. 2, p. 119-173, 2012.

ARAGÃO, A. M. et al. O Impulso da economia criativa no desenvolvimento regional do México. Revista GEINTEC, São Cristóvão/SE, v. 7, n. 1, jan.-mar., p.3634-3645, 2017.

ASUAGA, C. A quantificação do consumo cultural e as políticas culturais. In: CALABRE, L. (Org) Políticas culturais: informações, territórios e economia criativa. São Paulo: Itaú Cultural; Rio de Janeiro: Fundação Casa de Rui Barbosa, 2013.

BARBOSA-DA-SILVA, F. A (Org.). Indicador de desenvolvimento da economia da cultura. Brasília: IPEA, 2010.

BAUMOL, W. J. \& BOWEN, W.G. On the Performing Arts: The Anatomy of Their Economic Problems. New Jersey: Princeton University, 1965.

BENDASSOLLI, P. F. et al. Indústrias Criativas: definição, limites e possibilidades. Revista de Administração de Empresas (RAE), São Paulo, v. 49, n. 1, p. 10-18, 2009.

BOTELHO, I. Dimensões da Cultura e políticas públicas. São Paulo em Perspectiva, v. 15, n. 2, 2001.

Criatividade em pauta: alguns elementos em reflexão. In: BRASIL, Plano da Secretaria da Economia Criativa: políticas, diretrizes e ações, 2011-2014. Brasília: Ministério da Cultura, 2011.

Dimensões da Cultura: políticas culturais e seus desafios. São Paulo: Edições Sesc São Paulo, 2016.

BRASIL, F. G.; ALVES, R. P.; ALVES, J. P. A Economia Criativa No Brasil: Da Gênese, Ferramentas Políticas aos Desafios Futuros. Revista Gestão \& Políticas Públicas, v. 3, n. 2, p. 268-283, 2013.

COSTA, A. D.; SOUSA-SANTOS, E. R. Economia criativa no Brasil: quadro atual, desafios e perspectivas. Economia \& Tecnologia, v. 27, n. 7, out./dez., 2011.

ERNST \& YOUNG. Cultural times: The first global map of cultural and creative industries. Disponível em: 
<http://en.unesco.org/creativity/sites/creativity/files/cultural_times._the_first_global_map_of _cultural_and_creative_industries.pdf $>$. Acesso em: 04 jun. 2017.

FEDERAÇÃO DAS INDÚSTRIAS DO ESTADO DO RIO DE JANEIRO - FIRJAN. Mapeamento da Indústria Criativa no Brasil. 2016. Disponível em: <http://www.firjan.com.br/economiacriativa/download/mapeamento-industriacriativasistema-firjan-2016.pdf>. Acesso em: 03 jun. 2017.

GODOY, E. V.; SANTOS, V. M. Um olhar sobre a cultura. Educação em Revista, v.30, n. 3, p.15-41, 2014.

GOMES, C. L. Lazer, economia criativa e indústrias culturais e criativas: onde está o social? Licere, Belo Horizonte, v.17, n.4, dez/2015.

HARTLEY, J. Creative industries. London: Blackwell, 2005.

HOWKINS, J. The Creative Economy: how people make money from ideas. London: Penguin Books, 2001.

Books, 2013.

Economia Criativa: Como ganhar dinheiro com ideias criativas. São Paulo: M.

JAMBEIRO, O.; FERREIRA, F. Compreendendo as Indústrias Criativas de Mídia: contribuições da economia política da comunicação. Revista Comunicação Midiática, v. 7, n. 3, p. 178-194, set./dez., 2012.

JAMESON, F. A virada cultural: reflexões sobre o pós-modernismo. Tradução Carolina Araújo. Rio de Janeiro: Civilização Brasileira, 2006.

LEITÃO, C. S. et al. Indústrias criativas: alternativa de desenvolvimento regional. Liinc em Revista, v.7, n.2, setembro, 2011, Rio de Janeiro, p. 538 - 555.

LIPOVETSKY, G.; SERROY, J. A cultura-mundo, respostas a uma sociedade desorientada. São Paulo: Companhia das Letras, 2011.

LUGOBONI, L. F. et al. Economia criativa: aplicação nas empresas de TI. Future Studies Research Journal, São Paulo, v.6, n.1, p. 132 - 171, Jan./Jun. 2014.

MINTZ, S. W. Cultura: uma visão antropológica. Tempo, v. 14, n. 28, p. 223-237, 2010.

NICOLACI-DA-COSTA, A. M. O talento jovem, a internet e o mercado de trabalho da "economia criativa". Psicologia \& Sociedade, v. 23, n. 3, p. 554-563, 2011.

NOVY, J.; COLOMB, C. Struggling for the right to the (creative) city in Berlin and Hamburg: new urban social movements, new "spaces of hope"? International Journal of Urban and Regional Research, v. 35, n. 5, p. 1816-1838, 2013. 
OLIVEIRA, J. M.; ARAÚJO, B. C.; SILVA, L. V. Panorama da economia criativa no Brasil. Texto para Discussão 1880. IPEA/Brasília. Rio de Janeiro: IPEA, 2013.

PACHECO, A. P. C.; BENINI, E. G. Desenvolvimento da indústria criativa brasileira a partir dos pontos de cultura. Políticas Culturais em Revista, v. 1, n. 8, p. 121-135, 2015.

PAGLIOTO, B. F. Economia Criativa: mediação entre cultura e desenvolvimento. In.: LEITÃO, C.; MACHADO, A. F. Por um Brasil criativo: significados, desafios e perspectivas da economia criativa brasileira. Belo Horizonte: Código Editora, 2016.

PROCOPIUCK, M.; FREDER, S. M. Políticas públicas de fomento à economia criativa: Curitiba e contexto nacional e internacional. RBPD - Revista Brasileira de Planejamento e Desenvolvimento, v. 2, n. 2, p. 15-29, jul./dez. 2013.

REIS, A. C. F. Economia criativa como estratégia de desenvolvimento: uma visão dos países em desenvolvimento. São Paulo: Itaú Cultural, 2008.

RUBIM, A. A. C. Políticas culturais: entre o possível e o impossível. In: NUSSBAUMER, G. M. (Org.). Teorias e políticas da cultura: visões multidisciplinares. Salvador: EDUFBA, 2007, p.139-158.

RUBIM, A. A. C. Singularidades da formação em organização da cultura no Brasil. In: Organicom, ano 7, número 13, $2^{\circ}$ semestre, 2010. Disponível em <http://www.revistaorganicom.org.br/sistema/index.php/organicom>. Acesso em: 12 jan. 2018.

RÜDIGER, F. A Escola de Frankfurt. In: HOHLFELDT, A.; MARTINO, L. C.; FRANÇA, V. V. (orgs). Teorias da comunicação: conceitos, escolas e tendências. Petrópolis, RJ: Vozes, 2001. p.131-150.

SECRETARIA DA ECONOMIA CRIATIVA/MINC. Relatório de economia criativa 2010 - Economia criativa: uma opção de desenvolvimento viável. São Paulo: Itaú Cultural, 2012.

SILVA, F. R. M. As relações entre cultura e desenvolvimento e a economia criativa: reflexões sobre a realidade brasileira. Revista NAU Social, v. 3, n. 4, p. 111-121, maio/out., 2012.

UNCTAD - United Nations Conference on Trade and Development. Creative economy report 2008: the challenge of assessing the creative economy towards informed policymaking. Genebra: UNCTAD, 2008.

Creative Economy: a feasible development option. Geneva: United Nations, 2010.

Fortalecendo as indústrias criativas para o desenvolvimento. Geneva: United

Nations, 2011. 
UNESCO - United Nations Educational, Scientific and Cultural Organization. The 2009 Unesco framework for cultural statistics (FCS). Montreal: Unesco Institute for Statistics, 2009.

VAliati, L.; MOller, G. Economia Criativa, Cultura e Políticas Públicas. Porto Alegre: Editora da UFRGS/CEGOV, 2016.

VALIATI, L.; WINK JUNIOR, M. V. Indústria criativa no Rio Grande do Sul: síntese teórica e evidências empíricas. 2. ed. Porto Alegre: FEE, 2013.

WEBER, W. L. O Mosquito na Vidraça: a formação dos cidadãos à luz da teoria crítica da Escola de Frankfurt. In: ZUIN, A. Á. S.; PUCCI, B. RAMOSDE-OLIVEIRA, N. (orgs) A educação danificada: contribuições à teoria crítica da educação. Petrópolis/São Carlos: Vozes/UFSCAR, 1998. 